\title{
A musicalização como intervenção precoce junto a bebê com risco psíquico e seus familiares
}

\author{
Tatiane Medianeira Baccin Ambrós*1 \\ Aruna Noal Correa*2 \\ Luciéle Dias Oliveira*3 \\ Ana Paula Ramos de Souza*4
}

\begin{abstract}
A pesquisa analisou os efeitos da musicalização de bebês como intervenção precoce junto a um bebê com risco de evolução para o autismo, detectado pelos sinais PREAUT e pelos índicadores de referência ao desenvolvimento infantil, e seus familiares, inserido em grupo com outros dois bebês sem risco e suas mães. A intervenção apresentou-se efetiva para o estabelecimento do processo de alienação, $e$ também com progressos psicomotores, cognitivos e linguísticos. Pode-se concluir que a musicalização de bebê é uma alternativa de intervenção precoce em casos de risco psíquico.
\end{abstract}

Palavras-chave: Musicalização, intervenção precoce, risco psíquico, desenvolvimento infantil, autismo

\footnotetext{
*1 Psicóloga pela Universidade Federal de Santa Maria (Santa Maria, RS, Br).

*2 Universidade Federal de Santa Maria (Santa Maria, RS, Br).

*3 Universidade Federal de Santa Maria (Santa Maria, RS, Br).

${ }^{* 4}$ Universidade Federal de Santa Maria (Santa Maria, RS, Br).

$\mathrm{Br})$.
} 


\section{ARTIGOS}

\section{Introdução}

Considerando o aumento de diagnósticos de Transtornos do Espectro do Autismo (TEA) a partir de 2000 e a certeza de que a detecção e intervenção precoces levam a um melhor prognóstico dos casos (Laznik, 2013; Jerusalinsky, 2015), dois grupos de pesquisa, têm empreendido esforços, a partir de uma leitura psicanalítica, para detectar precocemente o risco de psicopatologias graves da infância a partir de dois instrumentos criados para inserção nas consultas pediátricas. No Brasil, Kupfer \& Volontolini (2005) abordam a possibilidade teórico-metodológica de criação dos Índices Clínicos de Risco ao Desenvolvimento Infantil (IRDIs), cuja pesquisa foi concluída em 2008 (Kupfer, 2008), e na França, o grupo de pesquisa e clínica que compõe a (Associación PREAUT, 2012) propôs os Sinais PREAUT, estes com objetivo mais específico de detecção de risco de evolução para o autismo.

Vários estudos têm comprovado a relevância dos IRDIs na detecção de risco ao desenvolvimento psíquico e sua correlação com alterações no exercício das funções parentais (Kupfer \& Bernardino, 2009; Beltrami et al., 2013), dificuldades alimentares, psicomotoras e de linguagem do bebê (Vendrúscolo et al, 2012; Flores \& Souza, 2014; Oliveira \& Souza, 2014; Vendrúscolo, 2014). O estudo de Ouss (2013) realiza uma primeira análise dos sinais PREAUT em sujeitos com síndrome de West observando que esses sinais possuem sensibilidade e especificidade para a detecção precoce do autismo.

Especificamente em relação ao autismo, há uma série de hipóteses atuais que afirmam que o autismo tem origem em uma falha pré-natal no desenvolvimento dos sistemas que programam o timing, a coordenação motora seriada, o controle prospectivo de movimentos e o controle da regulação afetiva das experiências, o que dificulta o engajamento do bebê em interações com seus cuidadores (Bullinger, 2006; Trevarthen \& Butt, 2013; Muratori, 2014). Os sinais neurológicos que emergem em vários trabalhos levariam ao que Golse (2013) propôs como dificuldades de mantelamento perceptivo e no estabelecimento da intersubjetividade primária. Tais bebês são pouco apetentes simbolicamente 
(Laznik, 2013), demonstrando pouco interesse pelo "manhês", forma particular e afetiva que as mães produzem com seus filhos, sobretudo quando eles respondem a elas com reciprocidade ou apetência simbólica (Laznik, 2013; Saint-Georges et al., 2013). Essa falta de apetência criará dificuldades na construção da intersubjetividade secundária, que segundo Golse (2013) é estudada pelo campo psicanalítico como dificuldades em estabelecer o terceiro tempo do circuito pulsional fruto do processo de alienação (Kupfer, 2000; Laznik, 2013; Jerusalinsky, 2015). Na visão de cognição social, cria-se um ciclo vicioso no qual a criança produz pequenas respostas, ou até ausência de respostas, às investidas parentais, o que dificulta a manutenção da interação e do investimento no "manhês" pelos pais (Cohen et al., 2013), isso porque esses bebês parecem investir mais em objetos do que no compartilhamento de ações (Saint-Georges et al., 2011).

A respeito deste processo Kupfer (2000), afirma que um equipamento falho do bebê, com o qual a função materna tem dificuldade ou até impossibilidade de operar, poderia obstaculizar o processo de constituição psíquica. Por isso, a detecção e intervenção precoce seriam uma forma de sustentar a mãe em sua função rumo ao encontro.

562 Na proposta da pesquisa que originou este estudo de caso, a música apresentou-se como possibilidade de intervenção precoce, diante de falhas nos sinais PREAUT e IRDIs que evidenciaram risco de evolução para autismo. A abordagem de musicalização de bebês da dra. Esther Sulzbacher Wondracek Beyer (Correa, Bellochio, 2010) apresentou-se promissora porque em sua rotina a música está inserida de modo harmônico com a movimentação corporal, favorecendo a integração sensorial e a possibilidade de o bebê liberar a córtex para entrar em relação, considerando os aspectos maturativos. Em relação aos aspectos afetivos envolvidos na constituição psíquica, os trabalhos de Carvalho (2012), Bialer (2014) e, principalmente, Januário e Tafuri (2010) anunciam que a música funciona como espaço de relação com crianças autistas em função do poder de fisgar a atenção do bebê, tanto pelo ritmo quanto pela melodia. Januario e Tafuri (2010) abordando o tema a partir da teoria de Winnicott, afirmam que a música pode se constituir como um holding potente junto ao bebê e sua mãe.

Motivadas por essa perspectiva e pelos resultados de Stahlschmidt (2002) com a abordagem de musicalização de Esther Beyer com bebês em risco psíquico, este estudo objetiva analisar os efeitos da musicalização como dispositivo de intervenção precoce junto a um bebê com risco de evolução para autismo e seus familiares. 


\section{ARTIGOS}

\section{Método}

A amostra deste estudo, qualitativo e longitudinal, foi constituída de um menino (I) com risco psíquico de evolução para autismo, avaliado pelos IRDIs e pelos sinais PREAUT, com três meses e alguns dias, proveniente de uma pesquisa maior na qual 140 bebês são acompanhados longitudinalmente de um a 24 meses, considerando os instrumentos citados, o teste de triagem de Denver II, análises das interações mãe (ou substituta)-bebê por meio de filmagens e entrevista inicial, e continuada, nas coletas. Estas incluem as faixas etárias de um mês, três meses, seis, nove, 12, 18 e 24 meses. Para este artigo foram utilizadas as análises relativas aos sinais PREAUT e IRDIs das coletas de três meses e um dia, seis meses e oito meses e um dia, dados obtidos na entrevista inicial.

Para constituir o grupo de musicalização além de I. e sua mãe (MI), dois outros bebês, um menino prematuro (K), sua mãe (MK) e uma menina nascida a termo (L) e sua mãe (ML) foram convidados a participar da pesquisa. As díades K-MK e L-ML não apresentavam risco psíquico quando avaliadas pelos IRDIs e sinais PREAUT. As principais características dos bebês e suas famílias estão resumidas no Quadro I.

\begin{tabular}{|c|c|c|l|l|l|l|}
\hline Sujeito & $\begin{array}{r}\text { Idade } \\
\text { inicial }\end{array}$ & $\begin{array}{c}\text { Idade } \\
\text { final }\end{array}$ & Familiares & $\begin{array}{l}\text { Idade dos } \\
\text { familiares }\end{array}$ & $\begin{array}{l}\text { Profissão } \\
\text { dos pais }\end{array}$ & $\begin{array}{c}\text { Frequência } \\
\text { aos encontros }\end{array}$ \\
\hline I & $5 \mathrm{~m} \mathrm{14d}$ & $9 \mathrm{~m}$ & $\begin{array}{l}\text { Mãe(MI) } \\
\text { Pai (PI) } \\
\text { Irmão } 1 \\
\text { (Irl1) } \\
\text { Irmão } 2 \\
\text { (IrI2) }\end{array}$ & $\begin{array}{l}26 \text { anos } \\
36 \text { anos } \\
07 \text { anos }\end{array}$ & $\begin{array}{l}\text { Do lar } \\
\text { Pedreiro } \\
\text { Estudante }\end{array}$ & $\begin{array}{l}\text { Nove encontros } \\
\text { Cinco com os } \\
\text { irmãos }\end{array}$ \\
\hline $\mathrm{K}$ & $8 \mathrm{~m} \mathrm{12d}$ & $1 \mathrm{a} 1 \mathrm{~m}$ & $\begin{array}{l}\text { Mãe (MK) } \\
\text { Pai (PK) }\end{array}$ & $\begin{array}{l}20 \text { anos } \\
26 \text { anos }\end{array}$ & $\begin{array}{l}\text { Do lar } \\
\text { Pedreiro }\end{array}$ & $\begin{array}{l}\text { Cinco } \\
\text { encontros }\end{array}$ \\
\hline $\mathrm{L}$ & $7 \mathrm{~m} \mathrm{11d}$ & $11 \mathrm{~m}$ & $\begin{array}{l}\text { Mãe (ML) } \\
\text { Pai (PL) } \\
\text { Irmão } \\
\text { (IrL) }\end{array}$ & $\begin{array}{l}33 \text { anos } \\
42 \text { anos } \\
08 \text { anos }\end{array}$ & $\begin{array}{l}\text { Do lar } \\
\text { Policial } \\
\text { Estudante }\end{array}$ & $\begin{array}{l}\text { Nove encontros } \\
\text { dois com o } \\
\text { irmão }\end{array}$ \\
\hline
\end{tabular}

Quadro I - Síntese de características dos bebês e família Legenda: $\mathrm{m}=$ =meses, $\mathrm{d}=$ dias, $\mathrm{a}=\mathrm{anos}, \mathrm{EMI}=$ ensino médio incompleto, $\mathrm{EMC}=$ =nsino médio completo Fonte: Dados da pesquisa elaborado pela autora 
O projeto foi aprovado seguindo a resolução 466/12 e compõe uma pesquisa maior aprovada no CEP-UFSM sob CAE: 28586914.0.0000.5346. Por isso, aos voluntários, responsáveis pelos bebês, foram esclarecidos os objetivos e procedimentos da pesquisa; além disso, lhes foi lido o termo de consentimento livre e esclarecido que os mesmos assinaram após concordarem com sua participação e de seus bebês. Nesse mesmo dia responderam a uma entrevista semiestruturada para obtenção de dados sociodemográficos, obstétricos e psicossociais. Os voluntários foram captados no teste do pezinho realizado na Unidade Básica de Saúde (UBS) na qual também foram realizados o grupo de musicalização e as filmagens da coleta maior. Os demais protocolos foram aplicados antes e após as filmagens e, em caso de dúvidas, mais de um examinador pode conferir os valores atribuídos por meio da visualização dos filmes.

Antes dos encontros de musicalização, o ambiente era organizado em uma sala de uso coletivo em uma Unidade Básica de Saúde, com disponibilização de colchonetes e almofadas em círculo que previa a acomodação das díades, da pedagoga responsável e da pesquisadora. Todos os encontros foram filmados para análise posterior, com duas câmeras (uma de visão geral do grupo e uma mais próxima a I e MI).

A escolha das atividades de musicalização (resumidas no Quadro 2) se baseou naquelas que, da rotina proposta por Esther Beyer, pudessem favorecer condutas intersubjetivas e a receptividade dos bebês às pessoas.

\begin{tabular}{|c|c|c|}
\hline Atividade & Materiais e Posicionamento & Procedimentos \\
\hline $\begin{array}{l}\text { Canção de } \\
\text { entrada/ }\end{array}$ & $\begin{array}{l}\text { Bebês sentados à frente das mães em } \\
\text { roda, de frente para a professora. Todos } \\
\text { em círculo de modo que todos possam } \\
\text { se ver. }\end{array}$ & $\begin{array}{l}\text { A professora cumprimenta } \\
\text { falando e depois cantando: "Oi" } \\
\text { diz o nome da criança e da } \\
\text { mãe que bom que estás aqui. }\end{array}$ \\
\hline $\begin{array}{l}\text { Balões em } \\
\text { movimento }\end{array}$ & $\begin{array}{l}\text { Balões, tule, música clássica, aparelho de } \\
\text { som, voz, movimento corporal, interação } \\
\text { bebê-balão e adulto-balão-bebê. } \\
\text { Os bebês ficam deitados em um tapete, } \\
\text { acima deles um grande tule, sobre o } \\
\text { qual eles podem ver balões coloridos se } \\
\text { movimentando. }\end{array}$ & $\begin{array}{l}\text { Os balões são movimentados } \\
\text { pela profes sora e pela } \\
\text { psicóloga que sacodem o } \\
\text { tule ao ritmo da música. A } \\
\text { mãe neste momento mostra } \\
\text { os balões e conversa com a } \\
\text { criança. O movimento cessa } \\
\text { quando a música acaba e os } \\
\text { balões são entregues aos } \\
\text { bebês. Em seguida a mãe } \\
\text { pega o balão e canta tocando } \\
\text { sob o corpo da criança. }\end{array}$ \\
\hline História "O trem" & $\begin{array}{l}\text { História, flauta de embolo, voz, } \\
\text { chocalhos, egg-shakers, movimentos } \\
\text { corporais, canção. Bebês sentados a } \\
\text { frente das mães, familiares, em círculo, } \\
\text { em contato visual com a professora. }\end{array}$ & $\begin{array}{l}\text { A professora conta uma } \\
\text { história de um trem e faz seus } \\
\text { barulhos por meio da voz, } \\
\text { chocalhos, egg-shakers, e } \\
\text { da flauta de êmbolo. A cada }\end{array}$ \\
\hline
\end{tabular}




\section{ARTIGOS}

\begin{tabular}{|c|c|c|}
\hline & & $\begin{array}{l}\text { movimento solicitado a mãe faz } \\
\text { os movimentos com a criança, } \\
\text { como por exemplo, "mexe prá } \\
\text { lá e pra cá". }\end{array}$ \\
\hline $\begin{array}{l}\text { Bolinhas, } \\
\text { massagem }\end{array}$ & $\begin{array}{l}\text { Música aparelho de som, voz, interação } \\
\text { adulto-bebê com o movimento-ritmo- } \\
\text { corpo. Criança deitada a frente da mãe. }\end{array}$ & $\begin{array}{l}\text { As mães passam as bolinhas de } \\
\text { massagem pelo corpo do bebê } \\
\text { enquanto ouvem uma música } \\
\text { clássica relaxante. }\end{array}$ \\
\hline Espelhos & $\begin{array}{l}\text { Música, canção, espelho. Criança } \\
\text { sentada de frente para a professora. }\end{array}$ & $\begin{array}{l}\text { As mães apresentam um } \\
\text { espelho de maquiagem aos } \\
\text { bebês, ao som de uma música } \\
\text { as crianças são instigadas } \\
\text { a olhar o espelho. A mãe } \\
\text { conversa perguntando quem é } \\
\text { que está ali? Como é lindo este } \\
\text { neném. }\end{array}$ \\
\hline $\begin{array}{l}\text { Instrumentos } \\
\text { musicais }\end{array}$ & $\begin{array}{l}\text { Música "Caranguejo peixe é", som, voz, } \\
\text { movimentos e interação adulo- bebê com } \\
\text { os instrumentos. Crianças sentadas na } \\
\text { roda de frente para a professora. }\end{array}$ & $\begin{array}{l}\text { Vários instrumentos musicais } \\
\text { são colocados no meio da roda } \\
\text { onde estão as crianças, em } \\
\text { seguida é solicitado que cada } \\
\text { criança pegue um instrumento } \\
\text { de sua preferência e comece } \\
\text { a tocar. }\end{array}$ \\
\hline Pula Pula & $\begin{array}{l}\text { Movimentos corporais, canção, interação } \\
\text { adulto-bebê, som voz. } \\
\text { Um pula-pula é colocado no centro da } \\
\text { sala e cada mãe com seu bebê no colo } \\
\text { vai até ele para pular. }\end{array}$ & $\begin{array}{l}\text { As crianças pulam no colo de } \\
\text { suas mães sobre um pula-pula } \\
\text { enquanto a professora canta: } \\
\text { vamos brincar de pula-pula, } \\
\text { vamos subindo e descendo, } \\
\text { com a mamãe também o (é dito } \\
\text { o nome da criança) vai pular. } \\
\text { Até que todas as crianças com } \\
\text { suas mães pulem. }\end{array}$ \\
\hline Pulguinha & $\begin{array}{l}\text { Som, toque, interação adulo- bebê, } \\
\text { excitação, movimentos, gestos. Criança } \\
\text { sentada a frente de sua mãe. }\end{array}$ & $\begin{array}{l}\text { A música a pulguinha é cantada, } \\
\text { as mães vão tocando no corpo } \\
\text { da criança, por exemplo, da } \\
\text { "da barriga pro umbigo, do pé } \\
\text { pula pra cabeça"... conforme a } \\
\text { música, tudo é muito prazeroso } \\
\text { pela criança. }\end{array}$ \\
\hline $\begin{array}{l}\text { Canção } \\
\text { despedida }\end{array}$ & $\begin{array}{l}\text { "Tchau!" } \\
\text { Crianças sentadas em círculo de frente } \\
\text { para a professora. }\end{array}$ & $\begin{array}{l}\text { A professora cumprimenta um a } \\
\text { um falando e depois cantando: } \\
\text { Tchau diz o nome da criança e } \\
\text { da mãe que bom que esteve } \\
\text { aqui, até semana que vem. }\end{array}$ \\
\hline
\end{tabular}

Quadro 2 - Rotina de Musicalização

Os encontros de musicalização foram filmados em sua íntegra, transcritos e analisadas levando em conta aspectos qualitativos como a adaptação 


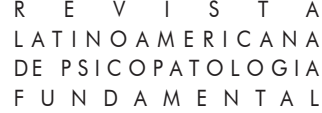

ativa realizada por MI, a presença de indícios de alienação por parte de I, e a interação da díade MI-I entre si e com os demais participantes do grupo, a partir das quais foram retiradas cenas para exemplificar a evolução de I e MI. Também foi realizada análise das filmagens dos encontros inicial, intermediário e final de musicalização, por meio da escala de Saint-Georges et al. (2011) que aborda comportamentos infantis e maternos a partir de uma perspectiva de cognição social.

Por fim, I. foi avaliado por uma terapeuta ocupacional, uma psicanalista aos 11 meses, para averiguar a estabilidade de sua evolução e a necessidade ou não de uma nova intervenção.

\section{Resultados e discussões}

O menino I. iniciou o grupo de musicalização quando estava com cinco meses e quatorze dias e a concluiu com nove meses. Ele é o terceiro filho do casal, nasceu de parto vaginal de uma gestação planejada. A mãe afirma tê-lo desejado muito e que o casal ficou muito feliz com a notícia da gravidez. MI parou de trabalhar para cuidar dos filhos após o nascimento de I, apesar das dificuldades financeiras familiares. O pai assumiu o sustento familiar.

Quando realizado o convite para participação no grupo de musicalização, não se mencionou a hipótese de risco psíquico de modo explícito, mas foi indicada a importância das aulas para desenvolvimento e socialização de I., considerando que as pesquisadoras percebiam certo retraimento no menino.

$\mathrm{Na}$ semana seguinte ao convite, MI chegou para a primeira aula silenciosa e começou a observar as demais mães e a se ambientar com os participantes. Durante as entrevistas, percebeu-se que a mãe sentia vergonha das pessoas, esforçava-se com um sorriso para começar as interações. Já I. chorou muito nas primeiras aulas, tendo dificuldade de participar do grupo. A cena 1 evidencia essa característica da mãe e do menino no primeiro encontro do qual participaram:

CENA 1: Olhando para os objetos na hora do Oi

"Na hora do "Oi", I. presta atenção na almofada colorida. A professora começa o "Oi" direcionando seu olhar para K. I. olha para a professora a seguir mas para sua mão que abana enquanto dá "Oi". Demonstra excitação 


\section{ARTIGOS}

com braços e instabilidade do tronco (balança para um lado e outro)l, enquanto olha a professora na atividade. No momento, em que a professora direciona o "Oi" para I., MI tenta estimulá-lo para que ele olhe para a professora, colocando seu braço sobre os braços de I. e tentando direcionar uma resposta de "Oi".

Percebe-se a dificuldade de I. em manter a atenção nas pessoas e de controle psicomotor. Em outros momentos, como na cena 2, ele chora incomodado com a possibilidade de ficar deitado sobre o colchonete:

CENA 2- A dificuldade de deitar e explorar os balões

"No momento de brincar com os balóes sobre o tule a mãe deita I., mas ele parece desconfortável para ficar deitado (está sem camisa). Olha os balões e estica o braço direito por algum tempo para tocar, depois fica mais incomodado e faz opistótono. A mãe o reposiciona e depois o coloca sentado, quando percebe que ainda está incomodado.... A mãe de I. (MI) está tensa e pouco confortável, pois tem dificuldades em tranquilizá-lo. Oferece dois balões em sequência, os quais ele deixa escapar sem explorar. I. choraminga."

Durante as escutas, realizadas em momentos anteriores aos encontros de musicalização, descobriu-se que MI teve uma infância difícil, não podendo conviver de forma harmoniosa com a mãe biológica. Foi adotada e depois sofreu muito quando voltou a morar com a mãe biológica. MI contou que a primeira gestação foi difícil, pois era jovem e sem experiência. Cabe ressaltar que os outros filhos, diferentemente de I., não apresentavam qualquer retraimento ou psicopatologia.

Considerando os IRDIs da fase 1, observou-se a ausência dos seguintes itens na análise das interações de I. e MI, antes da intervenção musical: 3. A criança reage ao "manhês"; 4. A mãe propõe algo à criança e aguarda sua reação; 5. Há troca de olhares entre a criança e a mãe. Considerando os resultados da pesquisa de Kupfer (2008), a ausência de apenas três IRDIs na fase 1,

${ }^{1}$ A instabilidade de tronco de I. relaciona-se ao fato de ainda não ter maturado para sentar sem apoio. No entanto, cabe ressaltar que seus movimentos globais tipo flaping e sua dificuldade de antecipar gestos para a preensão estavam de acordo com observações de Muratori (2014) sobre sinais precoces de autismo. Muratori, em reunião de pesquisa com a quarta autora, visualizou vídeos de I. confirmando esta análise. 


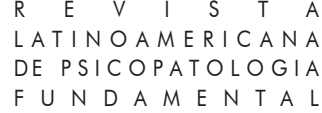

indicaria risco ao desenvolvimento mas não, necessariamente, risco psíquico, já que para aquela pesquisa os cinco primeiros IRDIs deveriam estar ausentes para prever psicopatologia grave. No entanto, I. apresentava evidente desconexão nos sinais PREAUT, que são mais sensíveis e específicos para risco de evolução para o quadro de autismo.

Embora MI conseguisse estabelecer as demandas e supor um sujeito em I., eixos percebidos pela presença dos IRDIs um e dois (1. Quando a criança chora ou grita a mãe sabe o que ele quer e 2. A mãe fala com a criança num estilo particularmente dirigido a ela (manhês)), ela já evidenciava certa ansiedade pela precariedade no retorno de I. às suas tentativas de comunicação, o que ficava evidente na ausência do índice quatro, pois não conseguia aguardar as respostas de I. MI propunha algo a I. e ela mesma respondia, sem aguardar a resposta do filho. Esse fato pode conectar-se às percepções de Saint-Georges et al. (2011) acerca da maior necessidade de regulação das mães sobre o comportamento de seus bebês, na análise de filmes familiares de bebês que se tornaram autistas. Esse parece ser o caso de MI que regula o comportamento de I. em função das dificuldades na sustentação do olhar e na falta de consistência nas respostas do menino, quando solicitado pela mãe.

Também é interessante notar que a ausência de olhares e a falta de reação ao "manhês" denunciavam o que seria encontrado nos sinais PREAUT, pois I. apresentou a resposta "não" para todos os itens quando testado na observação dos pesquisadores, antes da filmagem. I. não procurava espontaneamente a pesquisadora (1A) nem a mãe $(2 \mathrm{~A})$ nem sob estimulação $(1 \mathrm{~B}, 2 \mathrm{~B})$, o que lhe atribuiu uma pontuação zero na primeira parte do questionário. $\mathrm{O}$ mesmo ocorreu na segunda parte três (A, B, C) e quatro (A, B, C) que confirmam as observações iniciais desdobrando a análise em olhar, sorrir e suscitar troca prazerosa.

Durante a filmagem da pesquisa maior, observou-se um momento de reação ao "manhês" feito pela mãe, mas muito breve, com movimentação global do corpo e sem manutenção da interação além de três segundos. Também não endereçava, ou sustentava, o olhar para a mãe.

$\mathrm{Na}$ segunda fase de filmagens, em que são avaliados os IRDIs entre quatro e oito meses, I. foi avaliado entre os seis meses e um dia e sete meses e 29 dias, observou-se que a dupla não apresentava os seguintes índices: 6 . A criança utiliza sinais diferentes para expressar suas diferentes necessidades. 7. A criança reage (sorri, vocaliza) quando a mãe ou outra pessoa está se dirigindo a ela. 8. A criança procura ativamente o olhar da mãe, 


\section{ARTIGOS}

demonstrando que o risco psíquico se mantinha durante o início do processo de musicalização.

$\mathrm{Na}$ terceira fase da coleta maior, cujas análises foram realizadas entre oito meses e um dia e nove meses e 29 dias; em termos de sinais PREAUT percebeu-se que I. já reagia à estimulação da pesquisadora e da mãe, e também olhava espontaneamente para ambas. Não apresentava IRDIs ausentes. Nas cenas 3 e 4 exemplificam-se a evolução de I.- MI ao final dos encontros de musicalização.

CENA 3: I e MI desfrutando da aula

"I. ficava em pé no colo da mãe e levantava o menino próximo do rosto da mesma, passava a mão nos braços e nas costas da mãe. A mãe abraçava o filho. A seguir, pegou a almofada e iniciou uma brincadeira de esconde-esconde com o filho. Quando ele a achou, a mesma disse: "Achou, achou!". I. e a mãe sorriram, a mãe repetiu a brincadeira e I. gostou. Passa a mão no rosto da mãe, sorriu fisgado pelo gozo da brincadeira".

CENA 4: I vai atrás de L. espontaneamente na rotina dos balões

"L. engatinhou e ficou em frente a I. que olhava para ela. Depois, olhou para a professora e se aproximou das costas de L. passando a mão no braço da menina que estava se mexendo em busca de um balão. L. estava de costas para I. que seguia colocando a mão em suas costas e "batendo" como se estivesse chamando L."

As cenas 3 e 4 são evidências de que o processo de alienação (Kupfer, 2000) havia se estabelecido em I., o que se confirmou aos 11 meses quando foi avaliado por uma terapeuta ocupacional, como forma de controle do progresso de I., pois caso essa evolução não se estabilizasse ele passaria por um período de intervenção individual.

Essa avaliação demonstrou que o menino e a mãe já apresentavam diferenças quanto à postura e interação, quando comparadas ao período anterior aos encontros de musicalização.

No primeiro encontro o menino estava tímido, olhando muito para a avaliadora, com olhar de desconfiança, ou, ainda, muito sério. A mãe, para que interagisse, propôs cantar as músicas utilizadas nos encontros. I. as reconheceu e dançou timidamente. O menino olhava apaixonado para a mãe. Quando a mãe terminou, a terapeuta demonstrou sua vibração dizendo: "que 
havia sido lindo e que a mãe merecia um obrigado". O menino fez, então, cafuné com a cabeça no corpo da mãe, e enrolou-se na roupa dela.

Uma cena fundamental que demonstrou a instalação de I. na comunicação com o outro, foi quando ele chupava o dedo e a terapeuta pediu um pedaço, pois parecia gostoso. $\mathrm{O}$ menino provocou a terapeuta sugando mais forte seu dedo, até que deu um dedo para ela. A mãe apresentava-se naquele momento muito interpretativa, compreendendo tudo, e ajudando I. a se comunicar com a terapeuta.

No segundo encontro a mãe demonstrou ainda mais seu afeto, respeito e interação com o menino. A terapeuta pede permissão à mãe para se aproximar com um brinquedo e MI. devolve a pergunta a I., esperando sua resposta ela diz: "acho que ele está em dúvida".

Em seu relato, MI. afirmou que I. estava mais curioso e que antes era muito parado. Relata também que ele chamava a mãe de mama e o irmão de mano. Em sua fala MI. diz: "ele está mais solto". Também afirmou que as músicas estão inseridas na rotina familiar, e que, em especial, ele gostava da galinha pintadinha.

Nessa segunda sessão I. demonstrou ter estabelecido o terceiro tempo 570 do circuito pulsional (Laznik, 2013) quando oferece seu pé, sorrindo muito, para que a terapeuta continue um cafuné iniciado antes por ela, e quando imita a terapeuta na brincadeira de perguntar quem está fazendo barulho no outro lado da porta da sala. Essas observações confirmaram o que já tinha sido observado nas filmagens e avaliações anteriores da pesquisa: o processo de alienação se completara (Kupfer, 2000). Esse fato combina com o relato da mãe sobre I. estar mais ativo e curioso, e até com ciúme do irmão.

Considerando os resultados da escala de comportamentos materno-infantis de Saint-Georges et al. (2011), são expostos no Quadro 3 o resumo das análises nos encontros de musicalização.

Observa-se que as duas primeiras categorias, relativas aos objetos e a orientação às pessoas, ampliaram-se em termos qualitativos e quantitativos. No caso de objetos, houve uma duração média de exploração maior, sobretudo no quesito experiência física de prazer com o objeto. Em termos de orientação à pessoa, passou a acompanhar uma pessoa por oito segundos, o que não ocorria ao início. Os comportamentos de receptividade e busca a pessoas e, principalmente, os fatores intersubjetivos emergiram no encontro final.

Em relação à mãe, como se vê no Quadro 4, foi possível observar também uma evolução entre o primeiro encontro no qual MI. se apresentava tímida e menos ativa no uso de sua voz para atrair a atenção do filho, 


\section{ARTIGOS}

\begin{tabular}{|c|c|c|c|c|c|c|}
\hline \multirow[t]{2}{*}{ Comportamentos de I } & \multicolumn{2}{|c|}{$\begin{array}{l}\text { Encontro } \\
\text { inicial }\end{array}$} & \multicolumn{2}{|c|}{$\begin{array}{l}\text { Encontro } \\
\text { intermediário }\end{array}$} & \multicolumn{2}{|c|}{$\begin{array}{l}\text { Encontro } \\
\text { final }\end{array}$} \\
\hline & $n^{\circ}$ & DM & $n^{0}$ & DM & $n^{0}$ & DM \\
\hline \multicolumn{7}{|l|}{ Com objeto } \\
\hline $\begin{array}{l}\text { Explora o objeto com suas mãos, boca ou } \\
\text { ações para senti-lo (EO) }\end{array}$ & 6 & 15.64 & 1 & 0.46 & 2 & 29.05 \\
\hline $\begin{array}{l}\text { Busca o objeto com movimentos } \\
\text { espontâneos (MlObj) }\end{array}$ & 0 & 0 & 0 & 0 & 3 & 22.10 \\
\hline $\begin{array}{l}\text { Olha um objeto, mesmo sem estímulo ou } \\
\text { simplesmente olha em volta buscando } \\
\text { algo (OObjAR) }\end{array}$ & 1 & 14.36 & 0 & 0 & 3 & 7.62 \\
\hline $\begin{array}{l}\text { Tem prazer com experiência física ou } \\
\text { visual com o objeto (PrObj) }\end{array}$ & 0 & 0 & 0 & 0 & 1 & 53.75 \\
\hline $\begin{array}{l}\text { Busca um objeto com olhar prestando } \\
\text { atenção em um estímulo sensorial que } \\
\text { vem dele (OObjS) }\end{array}$ & 4 & 12.26 & 2 & 6.46 & 2 & 29.05 \\
\hline \multicolumn{7}{|l|}{ Orientação a pessoas } \\
\hline $\begin{array}{l}\text { Direciona-se ao estímulo sensorial vindo } \\
\text { de uma pessoa (OP) }\end{array}$ & 3 & 78.06 & 3 & 16.38 & 4 & 8.01 \\
\hline Acompanha com olhar uma pessoa (AOP) & 0 & 0 & 0 & 0 & 1 & 8.013 \\
\hline \multicolumn{7}{|l|}{ Receptividade a pessoas } \\
\hline $\begin{array}{l}\text { A criança realiza movimentos } \\
\text { espontâneos e intencionais para buscar } \\
\text { uma pessoa (BP) }\end{array}$ & 0 & 0 & 0 & 0 & 5 & 13.43 \\
\hline \multicolumn{7}{|l|}{ Buscando as pessoas } \\
\hline $\begin{array}{l}\text { Apresenta ações sintonizadas com as } \\
\text { solicitações afetivas relacionadas ao } \\
\text { humor do outro (SintP). }\end{array}$ & 0 & 0 & 0 & 0 & 5 & 15.5 \\
\hline $\begin{array}{l}\text { Tem experiência de prazer ou satisfação } \\
\text { física ou visual com uma pessoa (PRP), }\end{array}$ & 0 & 0 & 0 & 0 & 6 & 11.39 \\
\hline $\begin{array}{l}\text { Sorri intencionalmente para uma pessoa } \\
(\text { SoP) }\end{array}$ & 0 & 0 & 0 & 0 & 3 & 6.86 \\
\hline \multicolumn{7}{|l|}{ Intersubjetividade } \\
\hline Imita ação do outro (IA) & 0 & 0 & 0 & 0 & 1 & 49.45 \\
\hline $\begin{array}{l}\text { Para consultar familiar se pode pegar } \\
\text { um objeto, muda seu olhar do que está } \\
\text { fazendo em direção ao que o outro está } \\
\text { fazendo (MOP) }\end{array}$ & 0 & 0 & 0 & 0 & 1 & 9.62 \\
\hline $\begin{array}{l}\text { Vocaliza intencionalmente para o outro } \\
(\mathrm{NI})\end{array}$ & 0 & 0 & 0 & 0 & 19 & 1.77 \\
\hline
\end{tabular}

Quadro 3 - Análise da evolução de I nos encontros de musicalização

Legenda: $\mathrm{DM}=$ duração média em segundos

$$
\mathrm{n}^{\circ}=\text { número de comportamentos }
$$




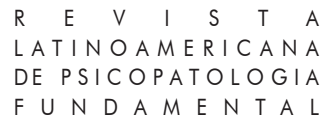

utilizando mais os objetos. Ela descobriu, durante os encontros, que sua voz podia ser atrativa e fisgar a atenção do filho. Isso demonstrou que I. havia suprimido os comportamentos de risco que criavam o ciclo vicioso descrito por Cohen et al. (2013) e também que ele aumentara a atenção a pessoas (Saint-Georges et al., 2011).

\begin{tabular}{|c|c|c|c|c|c|c|}
\hline \multirow{2}{*}{$\begin{array}{l}\text { Comportamentos de I } \\
\text { Regulação }\end{array}$} & \multicolumn{2}{|c|}{$\begin{array}{l}\text { Encontro } \\
\text { inicial }\end{array}$} & \multicolumn{2}{|c|}{$\begin{array}{c}\text { Encontro } \\
\text { intermediário }\end{array}$} & \multicolumn{2}{|c|}{$\begin{array}{l}\text { Encontro } \\
\text { final }\end{array}$} \\
\hline & $n^{\circ}$ & DM & $n^{\circ}$ & DM & $n^{\circ}$ & DM \\
\hline $\begin{array}{l}\text { Regula o comportamento infantil } \\
\text { excitando }\end{array}$ & 0 & 0 & 0 & 0 & 2 & 12.03 \\
\hline $\begin{array}{l}\text { Regula o comportamento infantil } \\
\text { acalmando }\end{array}$ & 2 & 93.87 & 1 & 111.21 & 0 & 0 \\
\hline Toque & 0 & 0 & 0 & 0 & 3 & 8.17 \\
\hline \multicolumn{7}{|l|}{ Vocalização } \\
\hline $\begin{array}{l}\text { Estimula a criança requerendo a atenção } \\
\text { da criança para vocalizar, vocalização } \\
\text { com manhês }\end{array}$ & 0 & 0 & 0 & 0 & 10 & 41,55 \\
\hline $\begin{array}{l}\text { Estimula a criança requerendo a atenção } \\
\text { da criança para vocalizar, vocalização } \\
\text { sem manhês }\end{array}$ & 1 & 189.75 & 3 & 5.57 & 5 & 11.66 \\
\hline \multicolumn{7}{|l|}{ Gestos ou demonstração } \\
\hline Busca atenção da criança gesticulando & 0 & 0 & 0 & 0 & 0 & 0 \\
\hline $\begin{array}{l}\text { Busca atenção da criança mostrando o } \\
\text { objeto }\end{array}$ & 1 & 189.75 & 3 & 9.91 & 0 & 0 \\
\hline Canto & 1 & 7.21 & 0 & 0 & 5 & 17.10 \\
\hline
\end{tabular}

Quadro 4 - Evolução de MI nos encontros de musicalização

Legenda: $\mathrm{DM}=$ duração média em segundos ou milisegundos $\mathrm{n}^{\circ}=$ número

Observou-se no decorrer dos encontros que MI se adaptava ativamente às demandas e dificuldades do filho oferecendo um setting adequado, retomando as palavras de Januário e Tafuri (2010), para que ele pudesse aprender, por exemplo, o ato de preensão. A repetição das atividades musicais, tanto favorecendo a exploração sonora quanto a organização das atividades por meio visual, podem ter favorecido também esse processo, pois nos encontros 


\section{ARTIGOS}

iniciais a mãe precisava auxiliá-lo a pegar os chocalhos e instrumentos e ao final ele já podia explorar os objetos sozinho.

A partir de tais observações é possível hipotetizar que I. conseguiu comodalizar perceptivamente e integrar as informações sensoriais (Golse, 2013) necessárias para que houvesse um sentido na exploração do objeto, o que se intensifica, gradativamente, a partir do sexto encontro em diante, encontro no qual evidencia-se o reconhecimento do próprio nome, um avanço significativo em termos simbólicos.

Em relação a MI. percebe-se que ela identificou que o "manhês" "fisgava" a atenção de seu filho, e como era uma mãe que fazia uma adaptação ativa ao seu bebê (Winnicott, 1999; Kruel, 2015), rapidamente modificou seu comportamento ao perceber que isso funcionava bem com I. Cabe ressaltar a importância do grupo como fator de estimulação para essa mãe modificar seu comportamento, sem que fosse necessário orientar verbalmente, pois a mudança se deu apenas pelo modelo positivo fornecido pela professora e por ML.

As observações de Bialer (2014), Carvalho (2012) e de Nascimento et al. (2015) sobre a importância da melodia e da repetição para a organização de sujeitos com autismo foi confirmada pela rotina de musicalização neste trabalho. Ela teve um efeito compensatório se considerarmos uma predisposição genética em I. (Kupfer, 2000; Jerusalinsky, 2015) para que a mãe pudesse descobrir que sua voz fisgava a atenção do filho e estabelecer os tempos pulsionais como pontua Laznik (2013). Disso, possivelmente, emergiu a possibilidade de comodalização perceptiva proposta por Golse (2013) e a reparação/compensação na construção e transição de uma intersubjetividade primária a uma secundária.

\section{Considerações finais}

Considerando o objetivo geral de analisar os efeitos de musicalização em um caso de risco psíquico (I-MI) foi possível observar a efetividade da proposta, pois na última coleta dos sinais PREAUT e dos IRDIs, realizada após a intervenção I. estava sem risco psíquico, o que se confirmou na avaliação da terapeuta ocupacional dois meses depois. A música foi uma forma de intervenção precoce positiva e efetiva, com a vantagem de não se apresentar como uma terapêutica tradicional, que, muitas vezes, não obtém a adesão dos familiares. Também, porque não despertou qualquer fantasma no imaginário familiar sobre um quadro de autismo. 


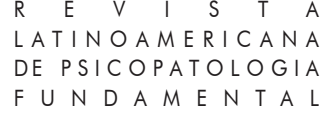

O estudo sugere que a proposta de Esther Beyer é ampla e adequada para embasar esse trabalho pelo fato de considerar simultaneamente aspectos cognitivos, afetivos e neuromaturativos. Ela possui espaços para adaptações e inovações, pois não é um método fechado, mas uma abordagem do desenvolvimento infantil em que a música é o tema principal que favorece o laço entre o bebê e seu outro primordial. Também reforça a relevância da inserção dos IRDIs e dos sinais PREAUT no trabalho de puericultura.

\section{Referências}

Associación Prèaut (2012). Homepage. Paris. Recuperado em 16 nov. 2012 de: $<$ http://www.preaut.fr/ $>$.

Beltrami, L (2013, agosto). Ansiedade materna puerperal e risco para o desenvolvimento infantil. Distúrbios da Comunicação, 25(2), 229-239.

Bialer, M (2014, out. dez.). A lógica do autismo: uma análise através da autobiografia de um autista. Psicologia em estudo, 19(4), 645-655.

Bullinger, A (2006). Approche sensorimotrice des troubles envahissants du dévelppment. Contraste, 25, 125-139.

Carvalho, G. M. M (2012, dez.). O ritmo como questão nas manifestações singulares do autista. Rev. Latinoam. Psicopatol. Fundam., 15(4), 781-797.

Cohen, D. et al (2013). Do parentese prosody and father's involvement in interacting facilitate social interaction in infants who later develop autism? Plos One, 8(5), 1-10.

Correa, A. N., \& Bellochio, C. R. (2010). Esther Beyer: contribuições para educação musical brasileira. Revista da ABEM, 23, 95-97.

Flores, M. R., \& Souza, A. P. R (2014). Diálogo de pais e bebês em situação de risco ao desenvolvimento. Revista CEFAC, 16, 840-852.

Golse, B. (2013). O autismo infantil, a intersubjetividade e a subjetivação entre as neurociências e a psicanálise. In I. K. Marin; R. O. Aragão (Orgs.), Do que fala o corpo do bebê. São Paulo, SP: Escuta.

Jerusalinsky, A. (2015). Tornar-se um sujeito é possível ou impossível para um autista? Quando e quem decide isso? In A. Jerusalinsky. Dossiê autismo. (pp. 22-55). São Paulo, SP: Instituto Langage.

Januário, L. M., \& Tafuri, M. I (2010). A relação transferencial com crianças autistas: uma contribuição a partir do referencial de Winnicott. Psic.Clín., 22(1), 57-70.

Kruel, C. S. (2015). O amadurecimento do bebê e a linguagem: uma leitura a partir de Winnicott e Benveniste, Tese de Doutorado em Distúrbios da Comunicação Humana, Universidade Federal de Santa Maria, RS. 


\section{ARTIGOS}

Kupfer, M. C. M. (2000). Notas sobre o diagnóstico diferencial da psicose e do autismo na infância. Psicologia USP, 11(1), 85-105.

Kupfer, M. C. M. (2008). Leitura da constituição e da psicopatologia do laço social por meio de indicadores clínicos: uma abordagem multidisciplinar atravessada pela psicanálise. Relatório científico final, PT Fapesp - n. 2003/09687, São Paulo, Instituto de Psicologia da Universidade de São Paulo, 2008.

Kupfer, M. C. M., \& Bernardino, L. M. F. (2009, mar.). As relações entre construção da imagem corporal, função paterna e hiperatividade: reflexões a partir da pesquisa IRDI. Rev. Latinoam. Psicopatol. Fundam., 12(1), 45-58.

Kupfer, M. C. M., \& Voltolini, R. (2005). Uso de indicadores em pesquisas de orientação psicanalítica: um debate conceitual. Rev. Psic.: Teoria e Pesq., 21(3), 359-364.

Laznik, M. C. (2013). A hora e a vez do bebê. São Paulo, SP: Instituto Langage.

Muratori, F. (2014). O diagnóstico precoce no autismo: guia prático para pediatras. Salvador: Ed. Núcleo Interdisciplinar de Intervenção Precoce de Bahia.

Nascimento, P. S. et al. (2015). Comportamentos de crianças do espectro do autismo com seus pares no contexto da educação musical. Ver. Brasileira de Educ. Especial, 21(1), 93-110.

Oliveira, L. D., \& Souza, A. P. R. (2014). O distúrbio de linguagem em dois sujeitos com risco ao desenvolvimento em uma perspectiva enunciativa de linguagem. Rev. CEFAC, 16(5), 1700-1712.

Ouss, L. et al. (2013). Infant's engagement and emotion as predictors of autismo or intelectual disability in West syndrome. European Child Adolesc Psuchiatry., 23(3), 143-149.

Saint-Georges, C. et al.(2011). Do parents recognize autistic deviant behavior long before diagnosis? Taking into account interaction using computational methods. Plos One, 8(10), 1-17.

Saint-Georges, C. et al. (2013). Sinais precoces do autismo: De onde vem? Para onde vão? In M. C. Busnel, \& R. G. Melgaço. O bebê e as palavras: uma visão transdisciplinar sobre o bebê. São Paulo, SP: Langage.

Stahlschmidt, A. P. M. (2002). A canção do desejo: da voz materna ao brincar com os sons, a função da música na estruturação psíquica do bebê e sua constituição como sujeito. Tese de Doutorado em Educação, Universidade Federal do Rio Grande do Sul, Porto Alegre, RS.

Thevarthen, C., \& Delafield-Butt, J. T. (2013). Autism as a developmental disorder in intentional movement and affective engagemente. Frontiers in integrative neurosciense, 7(17).

Vendrúscolo, J. F. et al. (2012). A relação entre o aleitamento, transição alimentar e 


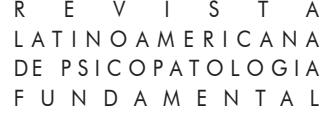

os indicadores de risco para o desenvolvimento infantil. Distúrb Comun., 24(1), 41-52.

Vendrúscolo, J. F. (2014). O brincar de sujeitos com risco psíquico: um olhar interdisciplinar. Dissertação de Mestrado em Distúrbios da Comunicação Humana, Universidade Federal de Santa Maria, Santa Maria, RS.

Winnicott, D. W. (1999). O bebê e suas mães. 4. ed. São Paulo: Martins Fontes.

\section{Resumos}

(Musicalization as early intervention for babies at psychic risk and their relatives)

This research analyzed the effects of musicalization on babies as early intervention for babies at risk of evolving towards autism, when this is detected by PREAUT signs and the risk indexes of child development, and their families, established in a group with two other babies who were not risk and their mothers. The intervention appeared to be effective in establishing the alienation process, and in psychomotor, cognitive and linguistic progress. We can thus conclude that babies' musicalization is an early intervention alternative in cases of psychological risk.

576 Key words: Musicalization, early intervention, psychological risk, child development, autism

(L'exposition à la musique comme intervention précoce chez un bébé à risque psychique et chez ses proches)

Cette étude analyse les effets de l'exposition de nourrissons à la musique comme intervention précoce chez un bébé à risque autistique - détecté par les signes PRÉAUT et les indicateurs de référence du développement de l'enfant - ainsi que chez ses proches, insérés dans un groupe avec deux autres bébés sans risque et leurs mères. L'intervention s'est montrée efficace pour l'établissement du processus d'aliénation, ainsi que pour le progrès psychomoteur, cognitif et linguistique. On conclut que l'exposition du bébé à la musique est une alternative d'intervention précoce en cas de risque psychique.

Mots clés: Exposition à la musique, intervention précoce, risque psychique, développement de l'enfant, autisme

(La musicalización como dispositivo de intervención precoz en el bebé con riesgo psíquico y en sus famílias)

La investigación analizó los efectos de la musicalización, como intervención precoz, en un bebé con riesgo de evolución de autismo, detectado por las señales PREAUT y a través de los indicadores de referencia del desarrollo infantil, y sus familiares. El bebé en riesgo y su familia fueron incluidos en un grupo de bebés sin riesgo y sus 


\begin{abstract}
ARTIGOS
madres. La intervención se mostró efectiva en cuanto al establecimiento del proceso de alienación, y con progresos psicomotores, cognitivos y lingüísticos. Se puede concluir que musicalización del bebé es una alternativa de intervención precoz en casos de riesgo psíquico.

Palabras clave: Musicalización, intervención precoz, riesgo psíquico, desarrollo infantil, autismo

(Musikalische Begleitung als frühe Intervention beim einem Kleinkind mit psychischem Risiko und seinen Angehörigen)

Dieser Artikel untersucht die Wirkungen der musikalischen Begleitung von Säuglingen als vorzeitige Intervention bei einem Kleinkind mit Autismus-Risiko und bei seinen Familienangehörigen. PREAUT-Indizien und Risikoanzeichen der Kinderentwicklung wurden benutzt, um das Risiko festzustellen. Das Kleinkind und seine Angehörigen waren Teil einer Gruppe, die außerdem zwei andere Babys ohne Risiko und ihre Mütter enthielt. Die Intervention war erfolgreich zur Feststellung des Alienationsprozesses und produzierte ebenfalls psychomotorische, kognitive und sprachliche Fortschritte. Man kann daraus schließen, dass die musikalische Begleitung von Kleinkindern eine alternative Form frühzeitiger Intervention bei psychischen RisikoFällen ist.
\end{abstract}

Schlüsselwörter: Musikalische Begleitung, vorzeitige Intervention, psychisches Risiko, 577 Kinderentwicklung, Autismus

Citação/Citation: Ambrós, T.M.B.; Correa, A. N.; Oliveira, L. D., \& Souza, A. P.R. de (2017, setembro). A musicalização como intervenção precoce junto a bebê com risco psíquico e seus familiares. Revista Latinoamericana de Psicopatologia Fundamental, 20(3), 560-578. http://dx.doi.org/10.1590/1415-4714.2017v20n3p560.10

Editores do artigo/Editors: Profa. Dra. Ana Maria Rudge e Profa. Dra. Sonia Leite

Recebido/Received: 16.11.2016 / 11.16.2016 Aceito/Accepted: 13.1.2017 / 1.13.2017

Copyright: (C) 2009 Associação Universitária de Pesquisa em Psicopatologia Fundamental/ University Association for Research in Fundamental Psychopathology. Este é um artigo de livre acesso, que permite uso irrestrito, distribuição e reprodução em qualquer meio, desde que o autor e a fonte sejam citados / This is an open-access article, which permits unrestricted use, distribution, and reproduction in any medium, provided the original authors and sources are credited. 


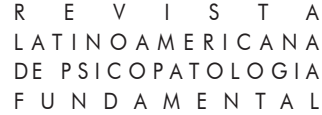

Financiamento/Funding: As autoras declaram não terem sido financiadas ou apoiadas / The authors have no support or funding to report.

Conflito de interesses/Conflict of interest: As autoras declaram que não há conflito de interesses / The authors have no conflict of interest to declare.

\section{Tatiane Medianeira Baccin Ambrós}

Psicóloga pela Universidade Luterana do Brasil - ULBRA; Mestre em Psicologia pela Universidade Federal de Santa Maria - UFSM (Santa Maria, RS, Br).

tatianeambros@yahoo.com.br

\section{Aruna Noal Correa}

Pedagoga; Doutora em educação pela Universidade Federal do Rio Grande do Sul (UFRGS- RS); Docente da Universidade Federal de Santa Maria - UFSM (Santa Maria, $\mathrm{RS}, \mathrm{Br})$.

arunanoal@hotmail.com

\section{Luciéle Dias Oliveira}

Fonoaudióloga da APAE-Santa Maria, Mestre e Doutoranda em Distúrbios da Comunicação Humana pela Universidade Federal de Santa Maria - UFSM (Santa Maria, $\mathrm{RS}, \mathrm{Br})$.

lu_fono1984@gmail.com

\section{Ana Paula Ramos de Souza}

Fonoaudióloga; Doutora em Linguística e Letras pela Pontifícia Universidade Católica do Rio Grande do Sul - PUC-RS) (Porto Alegre, RS, Br); Pós-doutora em Letras pela Universidade Federal do Rio Grande do Sul - UFRGS (Porto Alegre, RS, Br); Professora associada do departamento de Fonoaudiologia nos programas de pós-graduação em Psicologia e em Distúrbios da Comunicação Humana da Universidade Federal de Santa Maria - UFSM (Santa Maria, RS, Br).

ana.souza@ufsm.br

This is an open-access article, which permits unrestricted use, distribution, and reproduction in any medium for non-commercial purposes provided the original authors and sources are credited. 